\title{
Comparison of the effects of desflurane and sevoflurane on emergence characteristics in pediatric patients premedicated with ketamine
}

\author{
Hyojoong Kim ${ }^{1}$, Ki Hwa Lee ${ }^{1, \star}$, Yei Heum Park ${ }^{1}$, Soo Jung Lee ${ }^{2}$, Se Hun Kim¹, \\ Sang Eun Lee ${ }^{1}$, Yong Han Kim¹, Yu Kyung Jeon ${ }^{1}$
}

\author{
${ }^{1}$ Department of Anesthesiology and \\ Pain medicine, Haeundae Paik Hospital, \\ Inje University, Busan, Republic of Korea \\ ${ }^{2}$ Department of Ophthalmology, \\ Haeundae Paik Hospital, Inje University, \\ Busan, Republic of Korea
}

\section{*Correspondence \\ tedy333@paik.ac.kr \\ (Ki Hwa Lee)}

\begin{abstract}
Objectives: Desflurane may be useful for ambulatory anesthesia. However, desfluraneinduced airway irritability makes its use challenging, especially in children. Ketamine can be used to reduce separation anxiety and emergence agitation (EA). However, ketamine may increase bronchial secretions. This study compared desflurane with sevoflurane anesthesia, in terms of emergence time and EA, in preschool children with intravenous (IV) ketamine premedication.

Methods: Fifty-six children were scheduled for elective epiblepharon surgery. In the waiting room, ketamine $(1 \mathrm{mg} / \mathrm{kg})$ was intravenously administered to patients to reduce separation anxiety. After transport to the operating room, general anesthesia was induced with sevoflurane. The anesthetic agent was changed to desflurane in the desflurane group (group D), while sevoflurane was continued in the sevoflurane group (group S) during surgery. Emergence time (time to gag reflex and time to extubation) and EA (measured using the Pediatric Anesthesia Emergence Delirium [PAED] scale) were compared between the two groups. Respiratory complications were also recorded.

Results: Time to gag reflex $(611.1 \pm 288.9$ s vs. $275.0 \pm 126.7 \mathrm{~s}, P<0.001)$ and time to extubation $(756.3 \pm 267.2 \mathrm{~s}$ vs. $425.9 \pm 122.9 \mathrm{~s}, P<0.001)$ were significantly shorter in group D than group S. EA did not differ between the two groups. There were no severe respiratory complications.

Conclusions: Emergence time was shorter for desflurane anesthesia than sevoflurane anesthesia in preschool children who received IV ketamine premedication. Desflurane anesthesia with IV $0.1 \mathrm{mg} / \mathrm{kg}$ of ketamine premedication could be used safely in pediatric ophthalmic surgery; there were no significant respiratory events.
\end{abstract}

\section{Keywords}

Children; Desflurane; Ketamine; Sevoflurane

\section{Introduction}

It is important for parents that their children recover quickly and safely from general anesthesia (GA). Especially in preschool children, it can be difficult to maintain the airway because of frequent upper airway infections, and children in this age group are more likely to show emergence agitation (EA) after GA [1]. Pediatric patients with EA are often kicking and holding their head backwards, and do not make eye contact with their parents. EA prolonged the PACU stay, which may have resulted from additional pharmacologic treatment and delays reunion with parents [2]. The children and parents experience significant extremely distress during the perioperative period. Postoperative visual disturbance, inhalational anesthesia, and postoperative pain may be risk factors for EA [1, 3, 4]. Although total intravenous anesthesia can help to reduce EA [4], it is difficult to find a venous access in children.

Sevoflurane and desflurane, which have low blood solubility, are often used for pediatric anesthesia. These two halogenated anesthetics have lower blood-gas partition coefficients compared to older inhalation agents, and therefore shorten induction and recovery from anesthesia [5]. Each agent has its own benefits and limitations. Sevoflurane causes less bronchial stimulation and has a more prolonged extubation time than desflurane [6]. Although desflurane might provoke airway irritation, cough, and laryngospasm [7, 8], it can be used safely in pediatric ambulatory anesthesia [6]. In a metaanalysis of 1,273 pediatric patients, desflurane induced EA less frequently than sevoflurane [9]. Similarly, in a randomized controlled double-blind study of 144 adult patients having orthognathic surgery, desflurane anesthesia reduced the incidence of EA compared to sevoflurane anesthesia (24\% vs. $71 \%, P<0.001)[10]$. 
Preoperative anxiety may worsen EA after surgery [11], and can be a major challenge when performing surgical procedures on pediatric patients. Agents such as ketamine or midazolam have been used to reduce preoperative anxiety in the clinical setting. Ketamine $1.0 \mathrm{mg} / \mathrm{kg}$ administered before surgery has been shown to reduce separation anxiety, postoperative pain, and the incidence of EA, with no delay in recovery relative to ketamine $0.5 \mathrm{mg} / \mathrm{kg}$ or placebo during desflurane anesthesia [12]. Also, intravenous (IV) ketamine used as premedication can reduce EA compared to IV midazolam during sevoflurane anesthesia [13]. Lee et al. [14] reported that lack of premedication with midazolam may be a risk factor for EA in children.

Ketamine increases bronchial secretions due to an inhibitory effect on muscarinic receptors, and has a psychedelic effect through its action on the central nervous system [5]. We sought to determine if ketamine premedication for reducing separation anxiety could affect the emergence characteristics of desflurane or sevoflurane anesthesia in pediatric patients.

Therefore, this randomized trial compared the emergence characteristics of desflurane and sevoflurane anesthesia in preschool children who received preoperative IV ketamine $(1.0 \mathrm{mg} / \mathrm{kg})$. The primary outcome was the emergence time and the secondary outcome was EA.

\section{Methods}

This study was approved by the institutional review board of Haeundae Paik Hospital, Inje University (2016-07-011-001), and registered at https://clinicaltrials.gov (protocol number NCT02916407). The research is in accordance with the Helsinki Declaration of 1975, as revised in 2010.

\subsection{Study population}

Fifty-six patients were enrolled in the study. All patients were preschool-aged (3-6 years old) children with American Society of Anesthesiologists (ASA) physical status I, who were scheduled to undergo surgery to correct epiblepharon. Patients whose families refused to allow them to participate in this study, and patients who had severe acute upper respiratory infection or fever, were excluded.

\subsection{Data collection}

Patients were randomly assigned to Group D (desflurane group) or Group S (sevoflurane group). The randomization was performed using computer software. The attending anesthesiologist was informed about the study group assignment before administering the anesthetics. IV access was inserted with EMLA cream before surgery. IV ketamine $(1 \mathrm{mg} / \mathrm{kg}$ ) was administered to relieve anxiety caused by separation from the parents in the waiting room. The children were transferred to the operating room with pulse oximetry monitoring. The movement time from the waiting room to the operating room was about within 30 seconds to 1 minute. In the operating room, routine monitoring was performed, including electrocardiography, noninvasive blood pressure, pulse oximetry, and bispectral index (BIS). During face mask ventilation with oxygen $6 \mathrm{~L} / \mathrm{min}$, anesthesia was induced with atropine $0.01 \mathrm{mg} / \mathrm{kg}$, lidocaine $1 \mathrm{mg} / \mathrm{kg}$, propofol 2 $\mathrm{mg} / \mathrm{kg}$, and fentanyl $1 \mu \mathrm{g} / \mathrm{kg}$. IV rocuronium $0.6 \mathrm{mg} / \mathrm{kg}$ was administered to facilitate tracheal intubation. General anesthesia was maintained with sevoflurane in Group S and desflurane in Group D, to maintain the BIS value between 40 and 60. Blood pressure, heart rate (HR), peripheral oxygen saturation, and BIS were recorded throughout the surgery. All surgeries were performed by a single ophthalmologist. Volatile anesthetics were discontinued at the end of surgery, and patients were mechanically ventilated with $100 \%$ oxygen without any stimulation. The endotracheal tube was extubated after spontaneous ventilation and the airway reflex had fully returned. No stimulation was given until the first gag reflex. Emergence time was defined as time to gag reflex (the time from cessation of anesthetics to first gag reflex), and time to extubation (the time from cessation of anesthetics to extubation). The time from attaching the monitoring equipments to the extubation was recorded as the duration of anesthesia, and the time between the insertion and removal of the eyelid speculum was recorded as the duration of surgery. Cough, EA (measured using the Pediatric Anesthesia Emergence Delirium [PAED] scale) (Table 1) [15], and postoperative pain (measured using the Facial Pain Rating Scale [FPRS]) [16] were evaluated immediately after extubation.

\subsection{Emergence delirium, postoperative pain and cough scores}

Based on the study of Ozturk et al. [17], coughing was graded as 0 (no coughing), 1 (minimal coughing; 1-2 coughs), 2 (moderate coughing; 3-4 coughs), or 3 (severe coughing; $\geq 5$ coughs). The PAED and FPRS scores were recorded 10, 20, and $30 \mathrm{~min}$ after extubation in the post-anesthetic care unit (PACU). The occurrence of postoperative vomiting was also recorded. For patients who had severe EA (PAED score $>12$ ) [18], fentanyl $0.5 \mu \mathrm{g} / \mathrm{kg}$ was intravenously administered at 10min intervals. If EA did not subside despite three injections of IV fentanyl, propofol $1 \mathrm{mg} / \mathrm{kg}$ was intravenously administered [11].

\subsection{Statistics}

The sample size of this study was calculated based on the findings of a previous study [13]. We expected the difference in extubation time between groups to be $4.8 \mathrm{~min}$. A power analysis $(\alpha=0.05, \beta=0.20)$ showed that a total of 25 patients would be required for each group; assuming a dropout rate of $10 \%$, we enrolled 56 patients in the study (28 patients per group). The data are presented as frequency and percentage for categorical variables and mean \pm standard deviation (SD) for numerical variables. Differences in participant characteristics were compared among subgroups using the chi-squared test or Fisher's exact test for categorical variables, and the independent $t$-test or Mann-Whitney U test for continuous variables, as appropriate. The Shapiro-Wilk test was used to check the normality of the data. $P$ values $<0.05$ were considered statistically significant. All statistical analyses were performed using SPSS 25 statistical software (SPSS Inc., USA), and all tests were two-tailed. 
TA B L E 1. Pediatric Anesthesia Emergence Delirium (PAED) scale

$\begin{array}{lccccc}\text { The PAED scale } & \text { Not at all } & \text { Just a little } & \text { Quite a bit } & \text { Very much } & \text { Extremely } \\ \text { The child makes eye contact with the caregiver. } & 4 & 3 & 2 & 1 & 0 \\ \text { The child's actions are purposeful. } & 4 & 3 & 2 & 1 & 0 \\ \text { The child is aware of his/her surroundings. } & 4 & 3 & 2 & 1 & 0 \\ \text { The child is restless. } & 0 & 1 & 2 & 3 & 4 \\ \text { The child is inconsolable. } & 0 & 1 & 2 & 3\end{array}$

TA B L E 2. Demographic characteristics

\begin{tabular}{|c|c|c|c|c|}
\hline \multirow[b]{2}{*}{ Variable } & \multicolumn{4}{|c|}{ Group } \\
\hline & Overall & Group S & Group D & \\
\hline & $(\mathrm{n}=56)$ & $(\mathrm{n}=28)$ & $(\mathrm{n}=28)$ & $P$ \\
\hline Age (years) & $4.48 \pm 1.10$ & $4.32 \pm 1.06$ & $4.64 \pm 1.13$ & $.256^{4}$ \\
\hline \multicolumn{5}{|l|}{ Sex } \\
\hline Male & $29(51.8)$ & $15(53.6)$ & $14(50.0)$ & $.789^{1}$ \\
\hline Female & $27(48.2)$ & $13(46.4)$ & $14(50.0)$ & \\
\hline Height $(\mathrm{cm})$ & $108.23 \pm 8.72$ & $107.82 \pm 7.44$ & $108.64 \pm 9.96$ & $.728^{3}$ \\
\hline Weight (kg) & $19.38 \pm 4.12$ & $19.83 \pm 3.83$ & $18.94 \pm 4.41$ & $.254^{4}$ \\
\hline BMI $\left(\mathrm{kg} / \mathrm{m}^{2}\right)$ & $16.46 \pm 2.52$ & $17.05 \pm 3.12$ & $15.86 \pm 1.58$ & $.084^{4}$ \\
\hline Duration of surgery (min) & $32.59 \pm 13.38$ & $33.93 \pm 14.03$ & $31.25 \pm 12.81$ & $.313^{4}$ \\
\hline Duration of anesthesia (min) & $68.21 \pm 15.21$ & $70.71 \pm 14.70$ & $65.71 \pm 15.56$ & $.088^{4}$ \\
\hline \multicolumn{5}{|l|}{ Preoperative URI } \\
\hline Yes & $7(12.5)$ & $4(14.3)$ & $3(10.7)$ & $1.000^{2}$ \\
\hline No & $49(87.5)$ & $24(85.7)$ & $25(89.3)$ & \\
\hline
\end{tabular}

${ }^{1} P$ values were derived by chi-square test.

${ }^{2} P$ values were derived by Fisher's exact test.

${ }^{3} P$ values were derived by independent t-test.

${ }^{4} P$ values were derived by Mann-Whitney's $U$ test.

Shapiro-Wilk's test was employed for test of normality assumption.

URI: upper respiratory infection.

\section{Results}

A total of 56 patients were enrolled in this study (Fig. 1). The demographic characteristics of the patients are described in Table 2. There were no significant differences between the two groups. Four patients in Group S and three patients in Group D had mild upper respiratory infection at the time of preoperative assessment.

The GA recovery data are provided in Table 3. Emergence time and extubation time were significantly shorter in Group D than Group S $(P<0.001)$. Frequency and severity of cough after extubation did not differ significantly between the two groups.

Changes in HR and systolic blood pressure during surgery are depicted in Figs. 2 and 3, respectively. HR after extubation was significantly lower in Group S $(124.86 \pm 18.525 \mathrm{bpm})$ than Group D $(138.93 \pm 24.367 \mathrm{bpm})(P=0.018)$. Systolic blood pressure did not differ between the two groups.

The mean PAED score and severity of EA were described in Table 4. The mean PAED score did not significantly differ between the two groups immediately after extubation $(12.75$ \pm 7.33 vs. $11.39 \pm 7.79)$, at $10 \mathrm{~min}$ after extubation (3.68 \pm 4.59 vs. $3.43 \pm 5.47)$, at $20 \mathrm{~min}$ after extubation $(3.39 \pm$ 5.62 vs. $2.32 \pm 4.81)$, and at $30 \mathrm{~min}$ after extubation $(2.11 \pm$ 4.23 vs. $0.61 \pm 2.10$ ). The incidence of severe EA (PAED $>12)$ did not show a significant difference between Groups $\mathrm{S}$ and $\mathrm{D}(\mathrm{n}=15[53.6 \%]$ vs. $\mathrm{n}=13[46.4 \%]$ immediately after extubation, $P=0.5931 ; \mathrm{n}=1[3.6 \%]$ vs. $\mathrm{n}=4[14.3 \%] 10 \mathrm{~min}$ after extubation, $P=0.3522 ; \mathrm{n}=2[7.1 \%]$ vs. $\mathrm{n}=1[3.6 \%] 20$ min after extubation, $P=1.000$; and $\mathrm{n}=1[3.6 \%]$ vs. $\mathrm{n}=0[0 \%]$ $30 \mathrm{~min}$ after extubation, $P=1.000)$. The frequency injection of fentanyl and total amount of fentanyl were described in Table 5. The number of patients who received IV fentanyl administered did not differ between Groups S and D. No patients received IV propofol. The total amount of fentanyl was not significantly different between Groups S and D (9.82 $\pm 8.53 \mu \mathrm{g}$ vs. $8.77 \pm 7.80 \mu \mathrm{g})$.

There was no significant difference between Group S and $\mathrm{D}$ in the degree of postoperative pain, as assessed using the FPRS, except at 30 minutes after extubation (Table 6).

There were no major respiratory complications in either group. Laryngospasm developed in one patient in each group. 


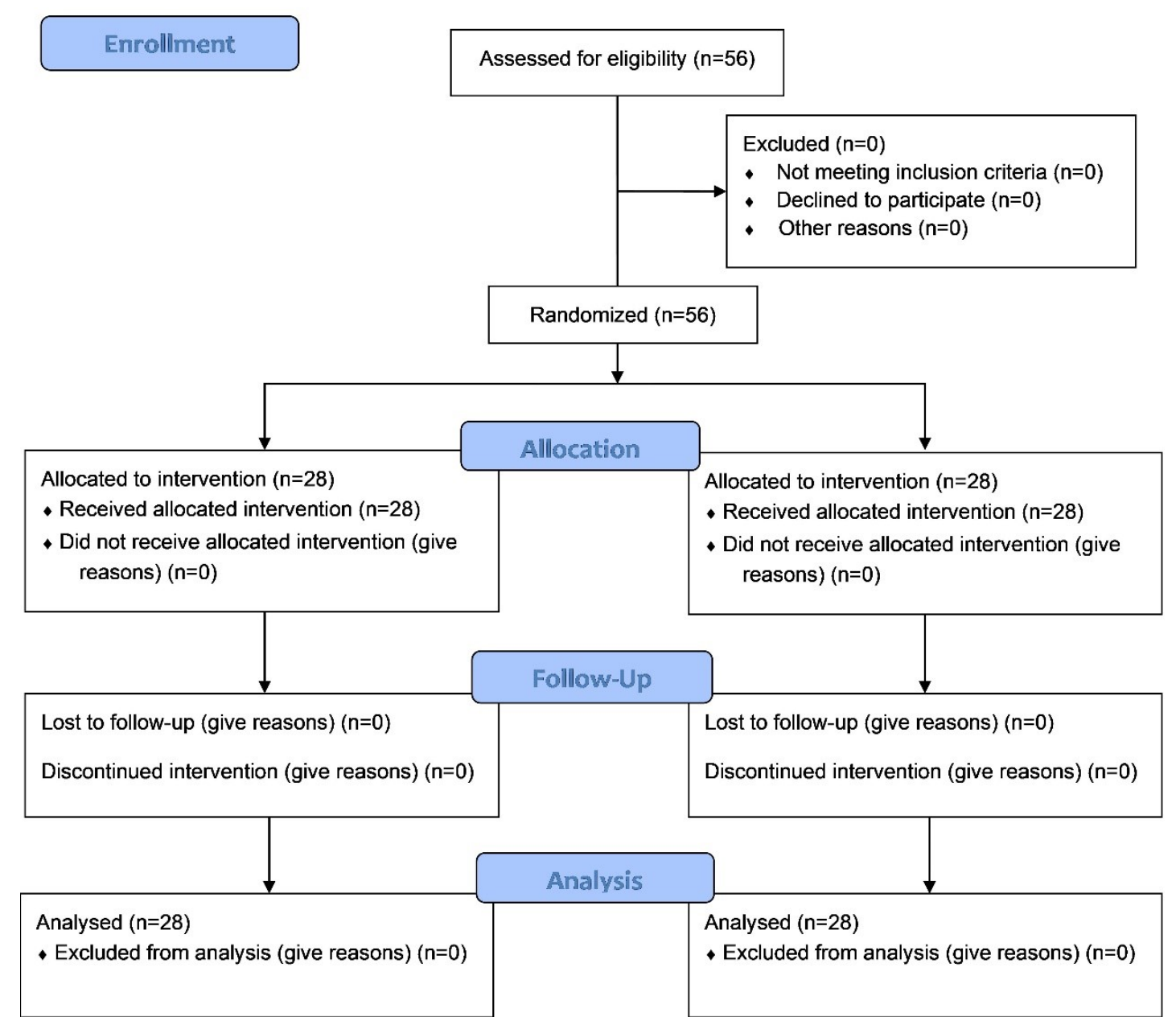

F I G U R E 1. CONSORT flow diagram.

TA B L E 3. Recovery profile

\begin{tabular}{|lcccc}
\hline Variable & Overall & Group S & Group D & \\
\hline & $(\mathrm{n}=56)$ & $(\mathrm{n}=28)$ & $(\mathrm{n}=28)$ & $P$ \\
\hline Time to gag reflex $(\mathrm{sec})$ & $443.05 \pm 278.62$ & $611.11 \pm 288.97$ & $275.00 \pm 126.68$ & $.000002^{4}$ \\
\hline Time to extubation $(\mathrm{sec})$ & $591.11 \pm 265.03$ & $756.25 \pm 267.22$ & $425.96 \pm 122.94$ & $.0000007^{3}$ \\
\hline Frequency cough & $3.54 \pm 5.41$ & $3.54 \pm 6.19$ & $3.54 \pm 4.62$ & $.570^{4}$ \\
\hline Grade cough & $1.30 \pm 1.25$ & $1.18 \pm 1.25$ & $1.43 \pm 1.26$ & $.481^{4}$ \\
\hline 0 & $22(39.3)$ & $12(42.9)$ & $10(35.7)$ & $.659^{2}$ \\
\hline 1 & $10(17.9)$ & $6(21.4)$ & $4(14.3)$ & \\
\hline 2 & $9(16.1)$ & $3(10.7)$ & $6(21.4)$ & \\
\hline 3 & $15(26.8)$ & $7(25.0)$ & $8(28.6)$ & \\
\hline Severity cough & & & & \\
$0-2$ & $41(73.2)$ & $21(75.0)$ & $20(71.4)$ & $.763^{1}$ \\
\hline 3 & $15(26.8)$ & $7(25.0)$ & $8(28.6)$ & \\
\hline
\end{tabular}

${ }^{1} P$ values were derived by chi-square test.

${ }^{2} P$ values were derived by Fisher's exact test.

${ }^{3} P$ values were derived by independent $t$-test.

${ }^{4} P$ values were derived by Mann-Whitney's U test.

Shapiro-Wilk's test was employed for test of normality assumption. 


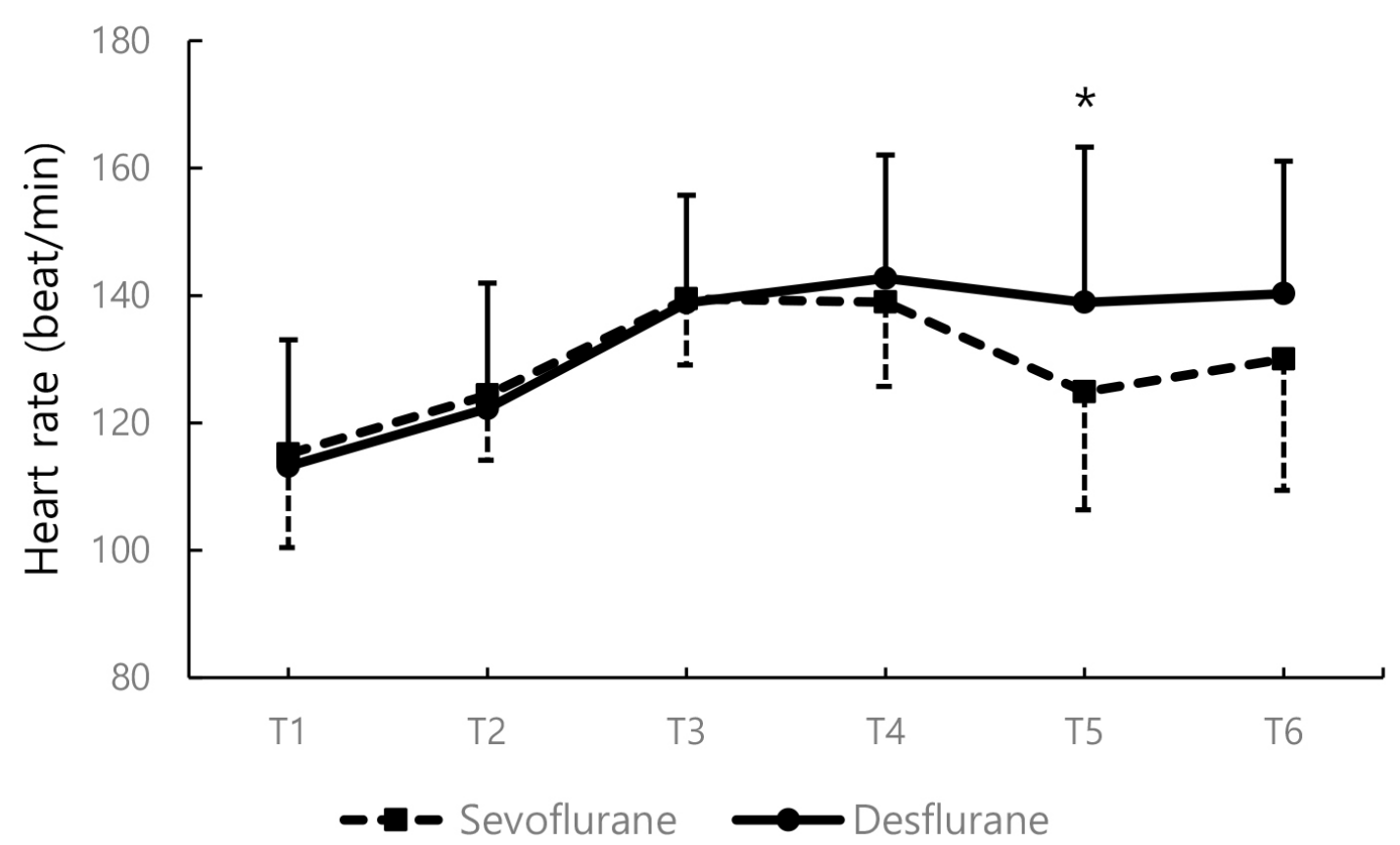

F I G URE 2. Comparison of heart rate between sevoflurane and desflurane group. T1: before induction of anesthesia, T2: after injection of intravenous anesthetics, T3: after tracheal intubation, T4: after skin incision, T5: after extubation, T6: just before leaving the operating room, $* P<0.05$ between the two groups. The error bars indicate standard deviation.

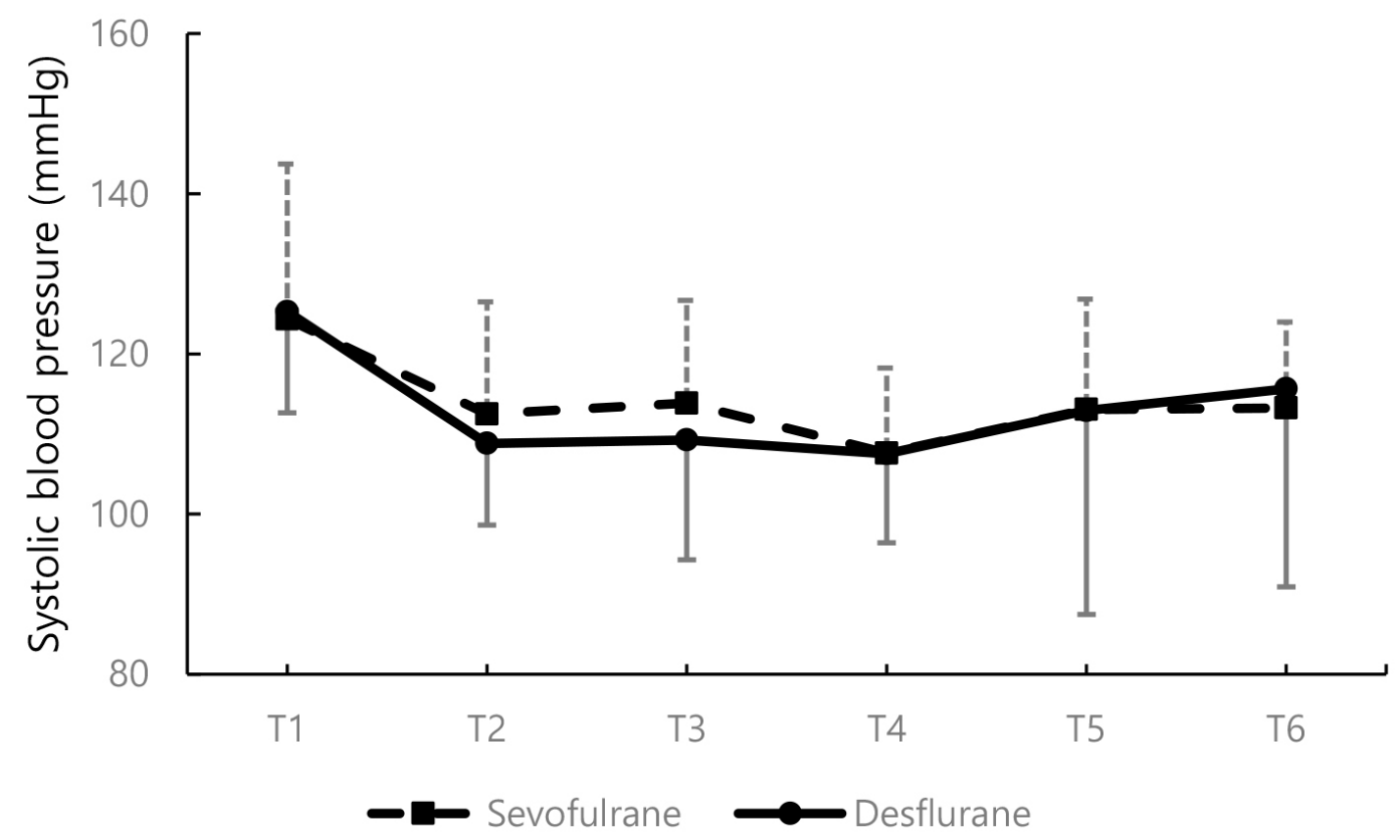

F I G URE 3. Comparison of systolic blood pressure between sevoflurane and desflurane group. T1: before induction of anesthesia, T2: after injection of intravenous anesthetics, T3: after tracheal intubation, T4: after skin incision, T5: after extubation, T6: just before leaving the operating room, ${ }^{*} P<0.05$ between the two groups. The error bars indicate standard deviation.

application of suction and mask ventilation. Postoperative vomiting within 24 hours after surgery did not develop in any patient in either group. No patient had a bad dream or psychedelic experience.

\section{Discussion}

Desflurane anesthesia had a much shorter emergence time than sevoflurane anesthesia when IV ketamine $1.0 \mathrm{mg} / \mathrm{kg}$ was preoperatively administered in preschool pediatric patients. There was no difference in the incidence of EA between the two groups.

Desflurane has a much lower blood-gas partition coefficient 
TA B L E 4. Pediatric Anesthesia Emergence Delirium (PAED) scale after extubation

\begin{tabular}{|lccc|}
\hline Time after extubation & $\begin{array}{c}\text { Group S } \\
(\mathbf{n}=\mathbf{2 8})\end{array}$ & $\begin{array}{c}\text { Group D } \\
(\mathbf{n}=\mathbf{2 8})\end{array}$ & $\boldsymbol{P}$ \\
\hline & Mean PAED score & \\
\hline $0 \mathrm{~min}$ & $12.75 \pm 7.33$ & $11.39 \pm 7.79$ & $.525^{1}$ \\
$10 \mathrm{~min}$ & $3.68 \pm 4.59$ & $3.43 \pm 5.47$ & $.456^{1}$ \\
\hline $20 \mathrm{~min}$ & $3.39 \pm 5.62$ & $2.32 \pm 4.81$ & $.321^{1}$ \\
\hline $30 \mathrm{~min}$ & $2.11 \pm 4.23$ & $0.61 \pm 2.10$ & $.052^{1}$ \\
\hline & Number of patients (PAED score $>12)$ & \\
\hline $10 \mathrm{~min}$ (yes/no) & $15 / 13$ & $13 / 15$ & $.593^{2}$ \\
\hline $20 \mathrm{~min}(\mathrm{yes} / \mathrm{no})$ & $1 / 27$ & $4 / 24$ & $.352^{3}$ \\
\hline $30 \mathrm{~min}(\mathrm{yes} / \mathrm{no})$ & $2 / 26$ & $1 / 27$ & $1.000^{3}$ \\
\hline
\end{tabular}

${ }^{1} P$ values were derived by Mann-Whitney's $U$ test.

Shapiro-Wilk's test was employed for test of normality assumption.

${ }^{2} P$ values were derived by chi-square test.

${ }^{3} P$ values were derived by Fisher's exact test.

TA B L E 5. Administration of fentanyl during recovery period

\begin{tabular}{|lccc|}
\hline Variable & Group S & Group D & \\
\hline Frequency of fentanyl & $(\mathbf{n = 2 8 )}$ & $(\mathbf{n = 2 8 )}$ & $\boldsymbol{P}$ \\
\hline 0 & $7(25.0)$ & $9(32.1)$ & $.639^{1}$ \\
\hline 1 & $15(53.6)$ & $12(42.9)$ & \\
\hline 2 & $5(17.9)$ & $7(25.0)$ & \\
\hline 3 & $1(3.6)$ & $0(0.0)$ & \\
\hline Total amount of fentanyl & $9.82 \pm 8.53$ & $8.77 \pm 7.80$ & $.677^{2}$ \\
\hline
\end{tabular}

${ }^{1} P$ values were derived by Fisher's exact test.

${ }^{2} P$ values were derived by Mann-Whitney's U test.

Shapiro-Wilk's test was employed for test of normality assumption.

TA B L E 6. Facial Pain Rating Scale after extubation

\begin{tabular}{|lccc|} 
Time after extubation & $\begin{array}{c}\text { Group S } \\
(\mathbf{n = 2 8})\end{array}$ & $\begin{array}{c}\text { Group D } \\
(\mathbf{n = 2 8})\end{array}$ & $\boldsymbol{P}$ \\
\hline $0 \mathrm{~min}$ & $6.04 \pm 3.05$ & $5.75 \pm 3.46$ & .855 \\
\hline $10 \mathrm{~min}$ & $2.79 \pm 3.27$ & $2.36 \pm 3.23$ & .526 \\
\hline $20 \mathrm{~min}$ & $2.36 \pm 3.39$ & $1.46 \pm 2.90$ & .243 \\
\hline $30 \mathrm{~min}$ & $1.50 \pm 2.20$ & $0.46 \pm 1.62$ & .016 \\
\hline
\end{tabular}

$P$ values were derived by Mann-Whitney's $U$ test.

Shapiro-Wilk's test was employed for test of normality assumption.

than sevoflurane (0.4 vs. 0.68 at $\left.37^{\circ} \mathrm{C}\right)$ [19]. Previous studies showed that desflurane anesthesia has a fast recovery time and no significant respiratory complications [6, 20]. Recovery from desflurane anesthesia was reportedly $20 \%$ faster in younger people than older ones ( $>65$ years) when comparing age related differences [21]. Our results are consistent with these earlier observations. IV ketamine premedication before surgery did not interfere with recovery from desflurane anes- thesia. The time to gag reflex and time to extubation were $45 \%-56 \%$ shorter in the desflurane than sevoflurane anesthesia group.

There are several reasons why EA occurs. Some studies have suggested that rapid recovery from GA might contribute to the occurrence of EA [14]. According to the meta-analysis [22], EA occurred more frequently with sevoflurane anesthesia than with halothane anesthesia in children. The pooled odds 
ratio for all studies was 2.21 , with a $95 \%$ confidence interval of 1.77-2.77 $(P<0.0001)$ [22]. In a meta-analysis of 1,273 pediatric patients performed in 2015 , desflurane induced EA less frequently than sevoflurane [9]. However, the incidence and severity of EA were comparable between desflurane and sevoflurane anesthesia in a 2016 meta-analysis, while emergence time was shorter in the desflurane group [23]. Compared to a previous study [13], the EA scoring scale was different in this study. The incidence and severity of EA may vary depending on the diagnostic scale used. Standardized clinical practice guidelines are needed to reduce the variation in EA incidence attributable to differences in assessment tools and definitions [14]. In addition, it is more difficult to distinguish between signs of EA and postoperative pain in preschool children, because they find it difficult to express themselves verbally [24].

Ketamine, a N-methyl-D-aspartate receptor antagonist and useful drug in pediatric anesthesia [25], is a racemic mixture consisting of two optical isomers. Ketamine has sedative and analgesic properties, and is associated with minimal respiratory and hemodynamic depression [5]. Ketamine also reduces opioid consumption [26] and PAED caused by fast-acting anesthetics [13]. Because of these characteristics, ketamine is widely used to sedate pediatric patients and reduce separation anxiety. Ketamine effectively reduced the incidence of EA, both when administered as a premedication and after GA induction [12]. In addition, preoperative IV ketamine has been reported to reduce separation anxiety and PAED in sevoflurane anesthesia [13]. The psychic disturbances following ketamine vary in incidence from less than 5\% to greater than 30\% [27]. Various factors associated with a higher incidence of psychic disturbances include age, sex, large doses of IV ketamine ( $>2 \mathrm{mg} / \mathrm{kg}$ ), rapid IV administration ( $>40 \mathrm{mg} / \mathrm{min}$ ), or a history of personality problems [27]. Serious side effects like hallucinations and bad dreams were not seen in this study.

Many anesthesiologists are cautious about airway reactivity and cough in desflurane anesthesia. Airway problem during GA is a big issue. Breath holding, excessive secretion, and desaturation occurred more frequently in desflurane anesthesia than sevoflurane anesthesia [8]. Surprisingly, in one report IV low-dose ketamine as premedication suppressed fentanylinduced cough [28]. Desflurane does not cause any significant changes in bronchial tone, while isoflurane and sevoflurane decrease airway resistance [19]. Copious secretion and mild desaturation occurred only in our sevoflurane anesthesia group. Higher incidence of coughing and breath-holding is a problem during transition to a 2 minimum alveolar concentration (MAC) of desflurane [29].

An increased concentration of volatile anesthetics is associated with a decrease in systemic vascular resistance, which leads to a reduction in blood pressure. There was no significant difference in HR or blood pressure between adult sevoflurane (1-2\%) and desflurane anesthesia (3-6\%) groups provided with $60 \%$ nitrous oxide [30]. When 1 MAC sevoflurane was compared to $1 \mathrm{MAC}$ desflurane in pediatric patients, there was no significant difference between the two groups in mean arterial blood pressure (MAP) or HR, except at 1 minute after tracheal intubation [28]. At that time, the desflurane group showed a significantly higher MAP and HR than the sevoflurane group.
These patients had received midazolam $0.06 \mathrm{mg} / \mathrm{kg}$ via intramuscular injection $30 \mathrm{~min}$ prior to surgery [28]. In the present study, although HR after extubation was significantly lower in the sevoflurane group, no severe bradycardia occurred in any patient. Intraoperative cardiovascular stability was achieved with both sevoflurane and desflurane, with systolic blood pressure and HR maintained within $\pm 20 \%$ of baseline values during anesthesia induction and maintenance.

The limitations of the present study are as follows: first, ophthalmologic procedures are associated with EA [2], and "visual preconditioning" can reduce the incidence of EA [3]. Congenital epiblepharon commonly occurs bilaterally [31]; and bilateral operations are more commonly performed in this study. The incidence of EA may have been higher than that seen in unilateral ophthalmic surgery; further studies are needed to confirm this. Second, fentanyl has sedative and analgesic effects. Preoperative $2.5 \mathrm{mcg} / \mathrm{kg}$ or postoperative 1 $\mathrm{mcg} / \mathrm{kg}$ of fentanyl is known to be effective for reducing the occurrence of EA [32, 33]. Therefore, the use of fentanyl may affect the likelihood of EA. Third, all pediatric patients were given IV ketamine premedication to reduce anxiety caused by separation from their parents. In future studies, it would be better to compare groups with and without ketamine.

\section{Conclusions}

In conclusion, maintenance of anesthesia with desflurane might provide rapid recovery from GA without increasing the incidence of EA or respiratory complications in preschool pediatric patients. Preoperative IV administration of $1 \mathrm{mg} / \mathrm{kg}$ of ketamine did not affect emergence in children undergoing sevoflurane or desflurane anesthesia.

\section{AUTHOR CONTRIBUTIONS}

Kim HJ and Lee KH contributed to the study conception and design. Lee SJ and Jeon YK contributed to data acquisition. LEE SE, Kim YH, and Park YH contributed to data analysis and interpretation. Kim SH contributed to statistical analysis and revisions. Lee $\mathrm{KH}$ contributed to funding acquisition. Kim HJ and Lee $\mathrm{KH}$ contributed to the drafting of the manuscript and its critical revision for important intellectual content. All authors have read and approved the final version of the manuscript.

\section{ETHICS APPROVAL AND CONSENT TO PARTICIPATE}

This study was approved by the institutional review board of Haeundae Paik Hospital, Inje University (2016-07-011-001), and registered at https://clinicaltrials.gov (protocol number NCT02916407). The research is in accordance with the Helsinki Declaration of 1975, as revised in 2010.

\section{ACKNOWLEDGMENT}

We would like to thank ace statistical consulting for statistical analysis. 


\section{FUNDING}

This work was supported by a grant from Research year of Inje University in 2018.

\section{CONFLICT OF INTEREST}

The authors declare that there is no conflict of interest regarding the publication of this article.

\section{DATA AVAILABILITY}

The data used to support the findings of this study are available from the corresponding author upon request.

\section{REFERENCES}

[1] Aono J, Ueda W, Mamiya K, Takimoto E, Manabe M. Greater incidence of delirium during recovery from sevoflurane anesthesia in preschool boys. Anesthesiology. 1997; 87: 1298-1300.

[2] Voepel-Lewis T, Malviya S, Tait AR. A prospective cohort study of emergence agitation in the pediatric postanesthesia care unit. Anesthesia and Analgesia. 2003; 96: 1625-1630.

[3] Lin Y, Shen W, Liu Y, Wang Q, Chen Q, Fang Z, et al. Visual preconditioning reduces emergence delirium in children undergoing ophthalmic surgery: a randomised controlled trial. British Journal of Anaesthesia. 2018; 121: 476-482.

[4] Chandler JR, Myers D, Mehta D, Whyte E, Groberman MK, Montgomery $\mathrm{CJ}$, et al. Emergence delirium in children: a randomized trial to compare total intravenous anesthesia with propofol and remifentanil to inhalational sevoflurane anesthesia. Pediatric Anesthesia. 2013; 23: 309-315.

[5] Mion G, Villevieille T. Ketamine pharmacology: an update (pharmacodynamics and molecular aspects, recent findings). CNS Neuroscience and Therapeutics. 2013; 19: 370-380.

[6] Kim EH, Song IK, Lee JH, Kim HS, Kim HC, Yoon SH, et al. Desflurane versus sevoflurane in pediatric anesthesia with a laryngeal mask airway: A randomized controlled trial. Medicine. 2017; 96: e7977.

[7] Zwass M, Fisher D, Welborn L, Coté C, Davis P, Dinner M, et al. Induction and maintenance characteristics of anesthesia with desflurane and nitrous oxide in infants and children. Anesthesiology. 1992; 76: 373378.

[8] Valley RD, Freid EB, Bailey AG, Kopp VJ, Georges LS, Fletcher J, et al. Tracheal extubation of deeply anesthetized pediatric patients: a comparison of desflurane and sevoflurane. Anesthesia and Analgesia. 2003; 96: 1320-1324.

[9] He J, Zhang Y, Xue R, Lv J, Ding X, Zhang Z. Effect of desflurane versus sevoflurane in pediatric anesthesia: a meta-analysis. Journal of Pharmacy \& Pharmaceutical Sciences. 2015; 18: 199-206.

[10] Choi GJ, Baek CW, Kang H, Park YH, Yang SY, Shin HY, et al. Emergence agitation after orthognathic surgery: a randomised controlled comparison between sevoflurane and desflurane. Acta Anaesthesiologica Scandinavica. 2015; 59: 224-231.

[11] Kain ZN, Caldwell-Andrews AA, Maranets I, McClain B, Gaal D, Mayes LC, et al. Preoperative anxiety and emergence delirium and postoperative maladaptive behaviors. Anesthesia and Analgesia. 2004; 99: 1648-1654.

[12] Jeong WJ, Kim WY, Moon MG, Min DJ, Lee YS, Kim JH, et al. The effect of ketamine on the separation anxiety and emergence agitation in children undergoing brief ophthalmic surgery under desflurane general anesthesia. Korean Journal of Anesthesiology. 2012; 63: 203-208.

[13] Kim KM, Lee KH, Kim YH, Ko MJ, Jung J, Kang E. Comparison of effects of intravenous midazolam and ketamine on emergence agitation in children: Randomized controlled trial. The Journal of International Medical Research. 2016; 44: 258-266.

[14] Lee SJ, Sung TY. Emergence agitation: current knowledge and unresolved questions. Korean Journal of Anesthesiology. 2020; 73: 471485.

[15] Sikich N, Lerman J. Development and psychometric evaluation of the pediatric anesthesia emergence delirium scale. Anesthesiology. 2004; 100: 1138-1145.

[16] Wong DL, Baker CM. Pain in children: comparison of assessment scales. Pediatric Nursing. 1988; 14: 9-17.

[17] Ozturk T, Acıkel A, Yılmaz O, Topçu I, Çevıkkalp E, Yuksel H. Effects of low-dose propofol vs ketamine on emergence cough in children undergoing flexible bronchoscopy with sevoflurane-remifentanil anesthesia: a randomized, double-blind, placebo-controlled trial. Journal of Clinical Anesthesia. 2016; 35: 90-95.

[18] Bajwa SA, Costi D, Cyna AM. A comparison of emergence delirium scales following general anesthesia in children. Paediatric Anaesthesia. 2010; 20: 704-711.

[19] Khan KS, Hayes I, Buggy DJ. Pharmacology of anaesthetic agents II: inhalation anaesthetic agents. Continuing Education in Anaesthesia Critical Care \& Pain. 2014; 14: 106-111.

[20] Dalal KS, Choudhary MV, Palsania AJ, Toal PV. Desflurane for ambulatory anaesthesia: a comparison with sevoflurane for recovery profile and airway responses. Indian Journal of Anaesthesia. 2017; 61: 315-320.

[21] Tsukamoto M, Yamanaka H, Yokoyama T. Age-related differences in recovery from inhalational anesthesia: a retrospective study. Aging Clinical and Experimental Research. 2018; 30: 1523-1527.

[22] Kuratani N, Oi Y. Greater incidence of emergence agitation in children after sevoflurane anesthesia as compared with halothane: a meta-analysis of randomized controlled trials. Anesthesiology. 2008; 109: 225-232.

[23] Lim BG, Lee IO, Ahn H, Lee DK, Won YJ, Kim HJ, et al. Comparison of the incidence of emergence agitation and emergence times between desflurane and sevoflurane anesthesia in children: a systematic review and meta-analysis. Medicine. 2016; 95: e4927.

[24] Dahmani S, Delivet H, Hilly J. Emergence delirium in children: an update. Current Opinion in Anaesthesiology. 2014; 27: 309-315.

[25] Jamora C, Iravani M. Unique clinical situations in pediatric patients where ketamine may be the anesthetic agent of choice. American Journal of Therapeutics. 2010; 17: 511-515.

[26] Bell RF, Dahl JB, Moore RA, Kalso E. Peri-operative ketamine for acute post-operative pain: a quantitative and qualitative systematic review (Cochrane review). Acta Anaesthesiologica Scandinavica. 2005; 49 : 1405-1428.

[27] White PF, Way WL, Trevor AJ. Ketamine-its pharmacology and therapeutic uses. Anesthesiology. 1982; 56: 119-136.

[28] Park JT, Lim HK, Jang K, Um DJ. The effects of desflurane and sevoflurane on the intraocular pressure associated with endotracheal intubation in pediatric ophthalmic surgery. Korean Journal of Anesthesiology. 2013; 64: 117-121.

[29] Arain SR, Shankar H, Ebert TJ. Desflurane enhances reactivity during the use of the laryngeal mask airway. Anesthesiology. 2005; 103: 495-499.

[30] Jindal R, Kumra VP, Narani KK, Sood J. Comparison of maintenance and emergence characteristics after desflurane or sevoflurane in outpatient anaesthesia. Indian Journal of Anaesthesia. 2011; 55: 36-42.

[31] Noda S, Hayasaka S, Setogawa T. Epiblepharon with inverted eyelashes in Japanese children. I. Incidence and symptoms. the British Journal of Ophthalmology. 1989; 73: 126-127.

[32] Cohen IT, Finkel JC, Hannallah RS, Hummer KA, Patel KM. The effect of fentanyl on the emergence characteristics after desflurane or sevoflurane anesthesia in children. Anesthesia and Analgesia. 2002; 94: 1178-1181.

[33] Cohen IT, Hannallah RS, Hummer KA. The incidence of emergence agitation associated with desflurane anesthesia in children is reduced by fentanyl. Anesthesia and Analgesia. 2001; 93: 88-91.

How to cite this article: Hyojoong Kim, Ki Hwa Lee, Yei Heum Park, Soo Jung Lee, Se Hun Kim, Sang Eun Lee, et al. Comparison of the effects of desflurane and sevoflurane on emergence characteristics in pediatric patients premedicated with ketamine. Signa Vitae. 2021;17(4):132-139. doi:10.22514/sv.2021.045. 